\title{
Chemosensitivity prediction in esophageal squamous cell carcinoma: Novel marker genes and efficacy-prediction formulae using their expression data
}

\author{
TATSUSHI SHIMOKUNI ${ }^{1,7}$, KEIJI TANIMOTO ${ }^{1}$, KEIKO HIYAMA ${ }^{1}$, KEIKO OTANI $^{2}$, MEGU OHTAKI ${ }^{2}$, \\ JUN HIHARA ${ }^{3}$, KAZUHIRO YOSHIDA ${ }^{3}$, TSUYOSHI NOGUCHI ${ }^{4}$, KATSUNOBU KAWAHARA ${ }^{4}$, \\ SHOJI NATSUGOE ${ }^{5}$, TAKASHI AIKOU ${ }^{5}$, YASUSHI OKAZAKI ${ }^{6}$, YOSHIHIDE HAYASHIZAKI ${ }^{6}$,

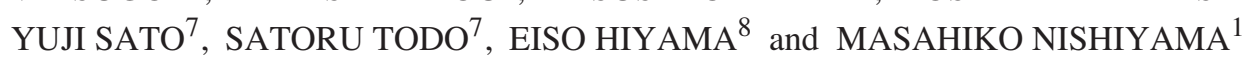 \\ Departments of ${ }^{1}$ Translational Cancer Research, ${ }^{2}$ Environmetrics and Biometrics, and ${ }^{3}$ Surgical Oncology, \\ Research Institute for Radiation Biology and Medicine, Hiroshima University, Hiroshima 734-8553; \\ ${ }^{4}$ Department of Surgery II, Faculty of Medicine, Oita University, Oita 879-5593; ${ }^{5}$ Department of Surgical Oncology, \\ Digestive Surgery, Graduate School of Medicine, Kagoshima University, Kagoshima 890-8544; ${ }^{6}$ Laboratory for \\ Genome Exploration Research Group, Riken Genome Science Center, Riken Yokohama Institute, Yokohama 230-0045; \\ ${ }^{7}$ Department of General Surgery, Graduate School of Medicine, Hokkaido University, Sapporo 060-8638; \\ ${ }^{8}$ Natural Science Center for Basic Research and Development, Hiroshima University, Hiroshima 734-8551, Japan
}

Received December 9, 2005; Accepted January 30, 2006

\begin{abstract}
Esophageal cancer is a highly lethal disease and the optimal therapy remains unclear. Since adjuvant chemotherapy gives a better chance of survival, we attempted to develop a chemosensitivity prediction model to improve individual responses to therapy. Comprehensive gene expression analyses (cDNA and oligonucleotide microarrays) and MTT assay of 8 drugs in 20 KYSE squamous cell carcinoma cell lines were performed to distinguish candidate marker genes whose expression levels reproducibly correlated with cellular drug sensitivities. After confirmation with real-time RT-PCR, we performed multiple regression analyses to develop drugsensitivity prediction formulae using the quantified expression data of selected marker genes. Using the same sets of genes, we also constructed prediction models for individual clinical responses to 5-FU-based chemotherapy using 18 cases. We selected 5 better marker genes, known as drug sensitivity determinants, identified 9 novel predictive genes for 4 of 8 anticancer drugs [5-FU, CDDP, DOX, and CPT-11 (SN-38)], and developed highly predictive formulae of in vitro sensitivities to the 4 drugs and clinical responses to 5-FU-based adjuvant
\end{abstract}

Correspondence to: Dr Masahiko Nishiyama, Department of Translational Cancer Research, Research Institute for Radiation Biology and Medicine, Hiroshima University, 1-2-3 Kasumi, Minami-ku, Hiroshima 734-8553, Japan

E-mail: yamacho@hiroshima-u.ac.jp

Key words: personalized medicine, drug sensitivity, gene expression, esophageal cancer, microarray chemotherapies in terms of overall and disease-free survivals. Our selected genes are likely to be effective drug-sensitivity markers and formulae using the 9 novel genes would provide advantages in prediction.

\section{Introduction}

Esophageal squamous cell carcinoma (ESCC) is rarely curable and only occasionally, if the patient is diagnosed very early, is there a chance of survival (1). Patients usually have rapid tumor recurrence and distant metastasis, even after curative surgery. A variety of treatments, such as chemotherapy, radiation, and their combinations, have been intensively investigated to date, and adjuvant (or neoadjuvant) chemotherapy for ESCC patients is now considered to be one of the most potent methods for lengthening survival times (2-4). However, the therapeutic outcome significantly varies, even among patients given the same therapy. The prediction of sensitivity to anticancer drugs and clinical outcomes of chemotherapy, which would allow selection of an optimal regimen for each individual, is urgently required to improve survival rates for ESCC patients.

The importance of prior laboratory prediction of individual drug response has stimulated research to identify the most reliable biomarkers, and several molecular markers and gene expression profiles in tumor tissues have shown potential for predictive benefit (5-8). None of these markers, however, is consistently critical in drug response for ESCC. Despite DNA chip technology, which enables us to overview a huge number of gene expressions simultaneously, the approach to predicting individual drug response by expression pattern, 'the snapshot profile', is increasingly recognized as being limited $(9,10)$. Drug sensitivity is determined by multiple genes, and gene expression 
profiles in response to drug exposure vary considerably among individuals even for the same drug or regimen. The ingenious and intricate mechanisms of drug sensitivity create obstacles to predicting the therapeutic efficacy of a drug, so a concise laboratory prediction system which can overcome the obstacles is eagerly awaited.

We have attempted to develop such a prediction system, and have shown the first concise prediction models of the in vitro activity for 8 drugs (5-FU, CDDP, MMC, DOX, CPT-11, SN-38, TXL, and TXT) using 19 cancer cell lines of various origin, along with individual clinical responses to 5-FU using the expression data of 12 genes selected solely from 50 function-proven genes (11). In that study, we used only cDNA microarray to distinguish potential prediction marker genes, followed by confirmation analysis with realtime RT-PCR. Consequently, there was no effective way to determine critical marker genes from the huge number of candidates, and we selected only functionally proven genes. However, it is obvious that more important marker genes may exist among the huge number of functionally unknown genes. Moreover, the biological behavior and molecular basis of cancer differ significantly according to its origin, so more prominent prediction biomarkers of drug response specific to each type of cancer may exist. Thus, we focused on ESCC and used oligonucleotide microarray analyses together with cDNA microarray to select more powerful drug-sensitivity markers. Using selected genes with and without proven functional significance to drug sensitivity, we developed an in vitro prediction model in $20 \mathrm{ESCC}$ cell lines and then constructed a clinical application model, a prediction system of therapeutic response to 5-fluorouracil (5-FU) based chemotherapy.

\section{Materials and methods}

Chemicals. 5-FU, Mitomycin C (MMC), and Doxorubicin (DOX) were kindly provided by Kyowa Hakko Kogyo Co., Ltd. (Tokyo, Japan). Cisplatinum (CDDP) and paclitaxel (TXL) were generously provided by Bristol-Myers K. K. (Tokyo, Japan). Docetaxel (TXT) was purchased from Aventis Pharma Ltd. (Tokyo, Japan), and irinotecan (CPT-11) and its active metabolite, SN-38, were obtained from Yakult Honsha Co., Ltd. (Tokyo, Japan). All other chemicals were of analytical grade and were purchased from Wako Pure Chemicals (Osaka, Japan) and Sigma (St. Louis, MO, USA).

Cells. A total of 21 cell strains/lines, 1 non-cancerous esophageal epithelial cell strain (HEEC-1) and 20 KYSE human esophageal squamous cell carcinoma cell lines (KYSE-30, $-140,-150,-170,-180,-200,-220,-350,-410,-450,-510,-520$, $-590,-770,-850,-890,-1170,-1190,-1250$, and -2270) were kindly provided by Dr Y. Shimada (Kyoto University, Kyoto, Japan). Human cancer cell lines were cultured in RPMI-1640 medium (Life Technologies, Inc., Grand Island, NY) containing $10 \%$ heat-inactivated fetal bovine serum (FBS; BioWhittaker, Verviers, Belgium) at $37^{\circ} \mathrm{C}$ in a humidified atmosphere of $5 \% \mathrm{CO}_{2}$ and maintained in continuous exponential growth by passage every 3 days. Non-cancerous HEEC-1 cells were cultured in Keratinocyte SFM medium with growth supplement containing $2.5 \mathrm{mg}$ EGF and $25 \mathrm{mg}$ bovine pituitary extract in
$500 \mathrm{ml}$ liquid basal medium (Gibco BRL, Rockville, MD) and expanded by passage twice in a week.

Patients and human tissue samples. Chemo-naïve patients with advanced esophageal cancer of which specimens could be collected at surgery were enrolled in the clinical study. All of the patients had histologically proven esophageal cancer (TNM/UICC classification: Stage III or IV) and had received curative esophagectomy with the subsequent 5-FU-based therapy as the post-operative adjuvant chemotherapy. The patients were all less than 80 years old (median 61, range 49-78) with performance status (World Health Organization: WHO) 0-2 without significant baseline-laboratory abnormalities, and life expectancy was estimated at more than 3 months. 5-FU was given by continuous intravenous administration at a dose of $250 \mathrm{mg} / \mathrm{m}^{2}$ for 28 days or 5-day continuous-infusion of $500 \mathrm{mg} /$ body/day per week for 28 days, as a combination regimen with cisplatin at an extremely low dose of $3 \mathrm{mg} / \mathrm{m}^{2}$ or $10 \mathrm{mg} /$ body/day. Total administered doses of 5-FU and CDDP ranged from 2,625 to $10,500 \mathrm{mg}$ (median, $10,000 \mathrm{mg}$; mean, $8,912 \mathrm{mg}$ ), and 26 to $200 \mathrm{mg}$ (median, $200 \mathrm{mg}$; mean, $143 \mathrm{mg}$ ), respectively. CT (computed tomography) scanning was performed every one or two months to evaluate disease-free survival (DFS). Overall survival (OS) was also estimated as the clinical response. Among the 18 tumor samples obtained from 17 patients, 14 tumors obtained early were used to yield the prediction formulae and 4 subsequently obtained tumors were used as test samples. Written informed consent was obtained from all patients, and the protocol was approved by our institutional ethics committees. The collected tumor specimens were stored at $-80^{\circ} \mathrm{C}$ until use.

Extraction and purification of RNA. For gene expression analysis, exponentially growing cultured cells $\left(2 \times 10^{6}\right)$ were collected after two-washings with PBS. The cell pellets were immediately frozen in liquid nitrogen, and stored at $-80^{\circ} \mathrm{C}$ until use. Cell pellets or frozen tissue samples $(\sim 40 \mathrm{mg})$ were powdered in liquid nitrogen, and total RNA was prepared using Qiagen RNeasy mini kit (Qiagen, Inc., Valencia, CA). For cDNA (complementary DNA) microarray analysis, mRNA was purified using $\mu$ MACS mRNA Isolation kit (Miltenyi Biotec, Bergisch Gladbach, Germany) according to the supplier's protocols. The quality of the RNA was checked using Agilent Technologies 2100 Bioanalyzer (Agilent, Palo Alto, CA).

cDNA microarray analysis. RIKEN human $21 \mathrm{~K}$ array containing 20,784 clones with positive and negative controls was used to analyze gene expression profiles of $20 \mathrm{KYSE}$ esophageal cancer cell lines using HEEC-1 as a reference sample. The target DNA used to construct human $21 \mathrm{~K}$ array was the glycerol stock of cDNA clones purchased from ResGen (Invitrogen Corp., Carlsbad, CA). Fabrication of the microarray, hybridization, washing, and detection of signal intensities were described previously $(12,13)$. Poly(A) RNAs from reference (HEEC-1) and sample (KYSE) cell lines were labeled, respectively, with Cy5-dCTP and Cy3-dCTP, by random-primed reverse transcription. Arrays were laserscanned using ScanArray 5000 ${ }^{\mathrm{TM}}$ confocal laser scanner (GSI Lumonics, Billerica, MA), and the images were analyzed using ScanAlyze $^{\mathrm{TM}}$ (Stanford University). All experiments were 
performed in duplicate. The amounts of mRNA were determined using the procedure proposed by Ohtaki et al, in which the signals of $\mathrm{Cy} 3$ and $\mathrm{Cy} 5$ were estimated as the value of $\left(\log _{2} s-\log _{2} b\right)$, where $s$ is spot mean intensity and $b$ is background median intensity. The signals were normalized by the procedure developed by Ohtaki et al and the normalized value was further standardized (14). The standardized value was obtained as follows and used as the amount of mRNA: $s^{C y 3 * *}$ $=\left(u_{i}{ }^{*}+v_{i}{ }^{*}\right) / 2$ and $s^{C y 5 * *}=\left(u_{i}^{*}-v_{i}{ }^{*}\right) / 2$, where $u_{i}{ }^{*}$, and $v_{i}^{*}$ are defined as $u_{i} / h$, and $\left[v_{i}-Q_{50}\left(v_{i}\right)\right] / h$, respectively. In the formulae, $u_{i}$ and $v_{i}$ represent the value of $\left(s^{C y 3 *}+s^{C y 5 *}\right)$ and $\left(s^{C y 3 *}-s^{C y 5 *}\right)$, while $Q_{75}\left(v_{i}\right), Q_{50}\left(v_{\mathrm{i}}\right)$, and $Q_{25}\left(v_{i}\right)$ indicate $75 \%, 50 \%$, and $25 \%$ point of $\left\{v_{i} \mid i=1 \ldots 21168\right\} . s^{C y 3 *}$ and $s^{C y 5 *}$ indicate normalized values of $\mathrm{Cy} 3$ and $\mathrm{Cy} 5$, and $h$ indicates the half-hinge value, which is $h=\left(Q_{75}\left(v_{i}\right)-Q_{25}\left(v_{i}\right)\right) / 2$.

Oligonucleotide array analysis. Codelink Expression Bioarray System (Amersham Bioscience, Tokyo, Japan) was used according to the manufacturer's protocol. Briefly, first-strand cDNA was generated from $1 \mu \mathrm{g}$ of total RNA of cell lines using reverse transcriptase and a T7 primer, and then secondstrand cDNA was produced using DNA polymerase mix and RNase H. cRNA (complementary RNA) was generated via an in vitro transcription reaction using T7 RNA polymerase and biotin-11-UTP (Perkin-Elmer, Boston, MA), which was quantified by spectrometry and checked using Agilent 2100 Bioanalyzer $^{\mathrm{TM}}$ (Agilent Technologies, Palo Alto, CA). Ten-micrograms of cRNA was then fragmented and hybridized to a Codelink ${ }^{\mathrm{TM}}$ Uniset Human 20K I Bioarray containing 19,981 probes with positive and negative bacterial control probes. After hybridization, the arrays were rinsed and labeled with Streptavidin-Cy5, scanned using Agilent DNA Microarray Scanner (Agilent), and then analyzed with Codelink Expression Analysis Software. Expression levels were normalized to the median expression value of the entire spot array. The microarray data were registered to the Gene Expression Omnibus under GE accession nos. GSE 2454 and GSE 2447 (http:// www.ncbi.nlm.nih.gov.geo/).

Real-time RT-PCR (reverse transcription-polymerase chain reaction). Two-micrograms of total RNA extracted from each cell line or tissue was reverse-transcribed using a HighCapacity cDNA Archive ${ }^{\mathrm{TM}}$ kit (Applied Biosystems), and then $1,000 \mathrm{x}$ aliquot of the cDNA (equivalent to $2 \mathrm{ng}$ total RNA) from cell lines and $200 \mathrm{x}$ aliquot of the cDNA (10 ng total RNA) from tissue were subjected to real-time RT-PCR using an ABI PRISM ${ }^{\text {Tм}}$ 7900HT sequence detection system (Applied Biosystems). Each reaction was carried out in triplicate or duplicate for cell lines and tissue, respectively, and averaged. The relative gene expression levels were calculated as a ratio to GAPD (glyceraldehyde-3-phosphate dehydrogenase gene) expression level.

Cytotoxicity assay. Drug-induced cytotoxicity was evaluated by conventional MTT [3-(4,5-dimethylthiazol-2-yl)-2,5diphenyltetrazonium bromide] dye reduction assay. Cells were seeded in 96-MicroWell Plates (NUNCLON, NUNC, Roskilde, Denmark) at a density of $4 \times 10^{3} /$ well in RPMI-1640 with $10 \%$ FBS (fetal bovine serum). After 24-h incubation, the medium was replaced and cells were exposed to the indicated drug concentrations for $72 \mathrm{~h}$, after which $10 \mu \mathrm{l}$ of $0.4 \%$ MTT reagent and $0.1 \mathrm{M}$ sodium succinate were added to each well. After 2-h incubation, $150 \mu \mathrm{l}$ of DMSO was added to dissolve the purple formazan precipitate. The formazan dye was measured spectrophotometrically (570-650 nm) using a MAXline $^{\mathrm{TM}}$ microplate reader (Molecular Devices Corp., Sunnyvale, CA). The cytotoxic effect of each treatment was assessed by $\mathrm{IC}_{50}$ value (inhibitory drug concentration of $50 \%$ cell growth: drug concentration of $50 \%$ optical density of control).

Rank correlation coefficient. Using rank correlation coefficient, the Spearman's correlation coefficient between ranks of two sets of measurements, we evaluated the statistical significance with a p-value obtained from the Monte Carlo method by generating null distribution under the hypothesis that there was no correlation between any two sets of measurements.

Multiple regression analysis. The relationship between $y$ (response variable) and $x_{i 1}, x_{i 2} \ldots x_{i p}$ (explanatory variables) is formulated in the linear model, $y_{i}=\varepsilon+\theta_{1} x_{i 1}+\theta_{2} x_{i 2}+\ldots+\theta_{p} x_{i p}$, where $\varepsilon$ is constant. Trimmed Least Squares Regression (TLSR) was performed to determine a set of effective genes that would satisfy the value of $\mathrm{IC}_{50}:\left(\theta_{1} \ldots \theta_{p}\right)$ were estimated from the data $\left(x_{i 1} \ldots x_{i p}\right)$ when we used gene expression levels and cellular sensitivity to drugs $\left(\mathrm{IC}_{50}\right.$ value for each drug), respectively as the explanatory and the response variables. The TLSR is a robust regression method based on an extended algorithm of LMSR (Least Median Squares Regression) by Rousseeuw, which explores models using masked samples with large residuals (15). We used the software, NLReg, developed by Ohtaki (http://apollo.rbm.hiroshima-u.ac.jp/), which implemented the robust regression analysis. Outliers were identified by referring to the value of AIC (Akaike's information criterion) for each sample or checking residuals graphically, and a set of effective genes that satisfied the value of $\mathrm{IC}_{50}$ was explored.

\section{Results}

Screening of prediction marker genes by comprehensive gene expression analysis. Comprehensive gene expression analyses using cDNA and oligonucleotide microarrays and MTT assay were performed in 20 ESCC cell lines to distinguish genes which were correlative in expression level with the cytotoxicities of 8 drugs. The standardized expression level of each gene and $\mathrm{IC}_{50}$ value for each drug in 20 cell lines were ranked, and then we determined the correlation between ranks of the two sets of measurements to select correlative genes with drug sensitivity.

The rank correlation analyses demonstrated a large number of correlative genes in cDNA and oligonucleotide microarrays, respectively: 500 and 520 for 5-FU, 494 and 997 for MMC, 644 and 978 for DOX, 479 and 867 for CDDP, 437 and 1,105 for TXL, 416 and 291 for TXT, 619 and 311 for CPT-11, and 509 and 1,007 for SN-38 ( $<<0.05$ ). From these, we selected reproducibly correlative genes with drug sensitivity by both microarray analyses as the first candidates for drug sensitivity 
Table I. Predictive marker genes for drug-induced cytotoxicity.

A) Genes known as drug sensitivity determinants.

Correlation coefficient $(\mathrm{R})$

\begin{tabular}{|c|c|c|c|c|c|c|}
\hline Gene & & 5-FU & DOX & CDDP & CPT-11 & $\overline{\mathrm{SN}-38}$ \\
\hline$B C L 2$ & $\begin{array}{l}\text { cDNA } \\
\text { Oligo } \\
\text { PCR }\end{array}$ & & $\begin{array}{c}- \\
0.505^{\mathrm{b}} \\
0.423^{\mathrm{b}}\end{array}$ & & & \\
\hline$D P Y D$ & $\begin{array}{l}\text { cDNA } \\
\text { Oligo } \\
\text { PCR }\end{array}$ & $\begin{array}{c}- \\
0.475^{\mathrm{b}} \\
0.682^{\mathrm{b}}\end{array}$ & & & & \\
\hline GSTP1 & $\begin{array}{l}\text { cDNA } \\
\text { Oligo } \\
\text { PCR }\end{array}$ & & & $\begin{array}{l}-0.525^{\mathrm{b}} \\
-0.430^{\mathrm{c}} \\
-0.426^{\mathrm{c}}\end{array}$ & & \\
\hline$M G M T$ & $\begin{array}{l}\text { cDNA } \\
\text { Oligo } \\
\text { PCR }\end{array}$ & & & & & $\begin{array}{c}- \\
0.412^{\mathrm{c}} \\
0.538^{\mathrm{b}}\end{array}$ \\
\hline$X R C C 1$ & $\begin{array}{l}\text { cDNA } \\
\text { Oligo } \\
\text { PCR }\end{array}$ & & & & $\begin{array}{c}0.589^{\mathrm{b}} \\
- \\
0.525^{\mathrm{b}}\end{array}$ & $\begin{array}{c}0.459^{\mathrm{b}} \\
- \\
0.392^{\mathrm{c}}\end{array}$ \\
\hline
\end{tabular}

B) The highest correlative genes for drug sensitivity.

Correlation coefficient $(\mathrm{R})$

\begin{tabular}{|c|c|c|c|c|c|c|}
\hline Gene & & $5-\mathrm{FU}$ & DOX & CDDP & CPT-11 & SN-38 \\
\hline$A R F R P 1$ & $\begin{array}{l}\text { cDNA } \\
\text { Oligo } \\
\text { PCR }\end{array}$ & & & $\begin{array}{l}0.615^{\mathrm{a}} \\
0.565^{\mathrm{a}} \\
0.440^{\mathrm{c}}\end{array}$ & & \\
\hline B4GALT5 & $\begin{array}{l}\text { cDNA } \\
\text { Oligo } \\
\text { PCR }\end{array}$ & $\begin{array}{l}0.632^{\mathrm{a}} \\
0.662^{\mathrm{a}} \\
0.772^{\mathrm{a}}\end{array}$ & & & & \\
\hline$C A L U$ & $\begin{array}{l}\text { cDNA } \\
\text { Oligo } \\
\text { PCR }\end{array}$ & & & & $\begin{array}{l}0.577^{\mathrm{a}} \\
0.577^{\mathrm{a}} \\
0.423^{\mathrm{c}}\end{array}$ & \\
\hline IFITMI & $\begin{array}{l}\text { cDNA } \\
\text { Oligo } \\
\text { PCR }\end{array}$ & & & $\begin{array}{l}-0.630^{\mathrm{a}} \\
-0.734^{\mathrm{a}} \\
-0.567^{\mathrm{a}}\end{array}$ & & \\
\hline KIAA0685 & $\begin{array}{l}\text { cDNA } \\
\text { Oligo } \\
\text { PCR }\end{array}$ & & & $\begin{array}{l}-0.567^{\mathrm{a}} \\
-0.570^{\mathrm{a}} \\
-0.462^{\mathrm{b}}\end{array}$ & & \\
\hline$N R C A M$ & $\begin{array}{l}\text { cDNA } \\
\text { Oligo } \\
\text { PCR }\end{array}$ & & $\begin{array}{l}0.645^{\mathrm{a}} \\
0.653^{\mathrm{a}} \\
0.493^{\mathrm{b}}\end{array}$ & & & \\
\hline SIPAIL2 & $\begin{array}{l}\text { cDNA } \\
\text { Oligo } \\
\text { PCR }\end{array}$ & & & $\begin{array}{l}-0.737^{\mathrm{a}} \\
-0.595^{\mathrm{a}} \\
-0.499^{\mathrm{b}}\end{array}$ & & \\
\hline$U G C G$ & $\begin{array}{l}\text { cDNA } \\
\text { Oligo } \\
\text { PCR }\end{array}$ & $\begin{array}{l}0.579^{\mathrm{a}} \\
0.578^{\mathrm{a}} \\
0.656^{\mathrm{a}}\end{array}$ & & & & \\
\hline$X B P 1$ & $\begin{array}{l}\text { cDNA } \\
\text { Oligo } \\
\text { PCR }\end{array}$ & $\begin{array}{l}0.776^{\mathrm{a}} \\
0.569^{\mathrm{a}} \\
0.804^{\mathrm{a}}\end{array}$ & & & & \\
\hline
\end{tabular}

cDNA, cDNA microarray analysis; oligo, oligonucleotide array analysis; PCR, real-time RT-PCR (linear regression analysis); ${ }^{\mathrm{a}} \mathrm{p}<0.01$; ${ }^{\mathrm{b}} 0.01 \leq \mathrm{p}<0.05 ;{ }^{\mathrm{c}} 0.05 \leq \mathrm{p}<0.1$. 
markers: The numbers were 30 for 5-FU, 43 for MMC, 78 for DOX, 38 for CDDP, 41 for TXL, 43 for TXT, 30 for CPT-11, and 56 for $\mathrm{SN}-38(\mathrm{p}<0.05)$.

Determination of prediction marker genes using real-time $R T-P C R$. The aim was to determine reliable prediction markers for 8 drugs from each of the 359 candidates. First, we focused on 50 genes whose functions as drug sensitivity factors had been clearly demonstrated in at least 2 reports among a total of 897 related papers (11), but the 359 candidates included very few genes known as drug sensitivity determinants. Although we extended the screening field to a range of $p<0.1$ in either cDNA or oligonucleotide microarray screening, no possible markers were found for TXL- and TXT-induced cytotoxicity, and the number of selected genes was only 11: DPYD (dihydropyrimidine dehydrogenase gene) and UMPS (uridine monophosphate synthetase gene) for 5-FU; $A B C B 1$ (ATPbinding cassette, sub-family $\mathrm{B}$, member 1 gene) for $\mathrm{MMC}$; $M Y C$ (v-myc avian myelocytomatosis viral oncogene homolog) and BCL2 (B-cell CLL/lymphoma 2 gene) for DOX, GSTP1 (glutathione S-transferase $\pi 1$ gene) and GCLC (glutamatecysteine ligase, catalytic subunit gene) for CDDP; TOPI (topoisomerase I gene) and XRCC1 (X-ray repair complementing defective repair in Chinese hamster cells 1 gene) for CPT-11; $M G M T\left(O^{6}\right.$-methylguanine-DNA methyltransferase gene), and POR [P-450 (cytochrome) reductase gene], TOP1, and $X R C C 1$ for SN-38 (16-37). These selected candidates were subjected to real-time RT-PCR analysis and we confirmed only 5 correlations: DPYD with 5-FU, BCL2 with DOX, GSTP1 with CDDP, XRCC1 with CPT-11, and MGMT with $\mathrm{SN}-38$, even when the selection criterion was determined as $\mathrm{p}<0.1$ in the linear regression analysis (Table IA).

The very small number of marker genes for limited drugs encouraged us to select additional potent marker genes via another approach, using only the data of expression-sensitivity correlation analysis. We selected genes which highly correlated with drug efficacy in the expression levels $(p<0.01)$ in both array screenings. A total of 20 genes among 359 candidates satisfied the selection criteria, and 9 genes were finally selected as the most potent markers of sensitivity to 4 drugs after the confirmation of correlations by real-time RT-PCR $(\mathrm{p}<0.1)$. They were B4GALT5 (UDP-Gal: BGlcNAc $\beta$ 1,4-galactosyltransferase, polypeptide 5 gene), UGCG (UDP-glucose ceramide glucosyltransferase gene), and XBP1 (X-box binding protein 1 gene) for 5-FU, NRCAM (neuronal cell adhesion molecule gene) for DOX, ARFRP1 (ADP-ribosylation factor related protein 1 gene), IFITM1 (interferon induced transmembrane protein 1 gene), KIAA0685, and SIPAIL2 (signalinduced proliferation-associated 1 like 2 gene) for CDDP, and $C A L U$ (calumenin gene) for CPT-11 (Table IB). Despite the relatively increased number of potent marker genes, no possible marker genes of MMC-, TXL-, TXT-, or additionally $\mathrm{SN}-38$-induced cytotoxicity were revealed in this approach.

Prediction formulae of sensitivity to 4 drugs in vitro. Selection of the truly significant genes for sensitivities to drugs would allow us to predict therapeutic response to these agents simultaneously, at which point we could understand their interplay in the expression. We therefore attempted to develop such a prediction model using expression data of the selected
Table II. Explanatory variables $\left(x_{\mathrm{ip}}\right)$ and estimated coefficients $\left(\theta_{p}\right)$ in in vitro prediction formulae for drug-induced cytotoxicity.

A) Prediction formulae using 5 functionally known genes

$\theta_{p}$

\begin{tabular}{lccccc}
\cline { 2 - 6 }$x_{i p}$ & $5-\mathrm{FU}$ & DOX & CDDP & CPT-11 & SN-38 \\
\hline $\ln [$ BCL2] & 0.071 & 0.159 & -0.468 & 0.086 & 0.139 \\
& $(0.300)$ & $(0.015)$ & $(0.001)$ & $(0.041)$ & $(0.380)$ \\
$\ln [D P Y D]$ & 0.108 & 0.029 & -0.032 & 0.007 & 0.036 \\
& $(0.000)^{\mathrm{b}}$ & $(0.039)$ & $(0.316)$ & $(0.404)$ & $(0.277)$ \\
$\ln [$ GSTP1] & 0.138 & -0.036 & -0.325 & -0.052 & -0.221 \\
& $(0.057)$ & $(0.576)$ & $(0.026)$ & $(0.217)$ & $(0.163)$ \\
$\ln [$ MGMT] & $-0.000^{\mathrm{a}}$ & 0.012 & 0.022 & 0.002 & 0.046 \\
& $(0.849)$ & $(0.006)$ & $(0.022)$ & $(0.382)$ & $(0.000)^{\mathrm{b}}$ \\
$\ln [$ XRCC1] & -0.115 & -0.104 & 0.066 & 0.215 & 0.390 \\
& $(0.249)$ & $(0.256)$ & $(0.762)$ & $(0.001)$ & $(0.091)$ \\
$\varepsilon_{\mathrm{i}}$ & 5.730 & 3.724 & 6.125 & 7.793 & 2.394 \\
\hline
\end{tabular}

B) Prediction formulae using 9 highly correlative genes.

\begin{tabular}{|c|c|c|c|c|c|}
\hline \multirow[b]{2}{*}{$X_{i p}$} & \multicolumn{5}{|c|}{$\theta_{p}$} \\
\hline & $5-\mathrm{FU}$ & DOX & CDDP & CPT-11 & $\mathrm{SN}-38$ \\
\hline \multirow[t]{2}{*}{$\ln [A R F R P 1]$} & -0.237 & -0.127 & 0.712 & -0.213 & \\
\hline & $(0.101)$ & $(0.305)$ & $(0.006)$ & $(0.005)$ & \\
\hline \multirow[t]{2}{*}{$\ln [B 4 G A L T 5]$} & 0.352 & 0.065 & -0.231 & -0.035 & \\
\hline & $(0.064)$ & $(0.661)$ & $(0.580)$ & $(0.675)$ & \\
\hline \multirow[t]{2}{*}{$\ln [C A L U]$} & -0.258 & -0.075 & -0.347 & 0.178 & \\
\hline & $(0.215)$ & $(0.676)$ & $(0.314)$ & $(0.082)$ & \\
\hline \multirow[t]{2}{*}{$\ln [I F I T M I]$} & -0.165 & -0.058 & -0.274 & -0.016 & \\
\hline & $(0.030)$ & $(0.341)$ & $(0.043)$ & $(0.649)$ & \\
\hline \multirow[t]{2}{*}{$\ln [K I A A 0685]$} & 0.294 & 0.366 & -0.708 & -0.016 & \\
\hline & $(0.342)$ & $(0.192)$ & $(0.221)$ & $(0.918)$ & \\
\hline \multirow[t]{2}{*}{$\ln [N R C A M]$} & 0.087 & 0.145 & -0.045 & 0.046 & \\
\hline & $(0.052)$ & $(0.000)^{\mathrm{b}}$ & $(0.565)$ & $(0.027)$ & \\
\hline \multirow{2}{*}{$\ln [S I P A 1 L 2]$} & -0.044 & -0.090 & 0.039 & 0.041 & \\
\hline & $(0.436)$ & $(0.051)$ & $(0.758)$ & $(0.120)$ & \\
\hline \multirow{2}{*}{$\ln [U G C G]$} & 0.470 & -0.081 & -0.164 & 0.145 & \\
\hline & $(0.030)$ & $(0.631)$ & $(0.678)$ & $(0.152)$ & \\
\hline \multirow[t]{2}{*}{$\ln [X B P 1]$} & 0.087 & -0.068 & 0.864 & -0.254 & \\
\hline & $(0.676)$ & $(0.679)$ & $(0.038)$ & $(0.012)$ & \\
\hline$\varepsilon_{\mathrm{i}}$ & 5.243 & 3.745 & 5.518 & 8.158 & \\
\hline
\end{tabular}

[ ], expression level of indicated gene; ${ }^{\mathrm{a}}-0.000$ : -0.0008852 ; ( ), p-value; ${ }^{b} 0.000$ : $<0.0005$.

genes, and performed multiple regression analysis to understand the interplay in the expression of the genes.

The expression levels of the selected genes quantified by real-time RT-PCR and cellular sensitivity to drugs $\left(\mathrm{IC}_{50}\right.$ value for each drug) were used as the explanatory variables $\left(x_{1}, x_{2}\right.$, $\left.\cdots, x_{p}\right)$ and the response variable $(y)$, respectively, and we estimated $\left(\theta_{1}, \cdots, \theta_{p}\right)$ of the formula in the linear model: $y_{i}=$ $x_{i 1} \theta_{1}+x_{i 2} \theta_{2}+\cdots+x_{i p} \theta_{p}+\varepsilon_{i}(i=1,2, \cdots, n)$, where $\varepsilon_{i}$ is a random error, using NLReg software. 
A
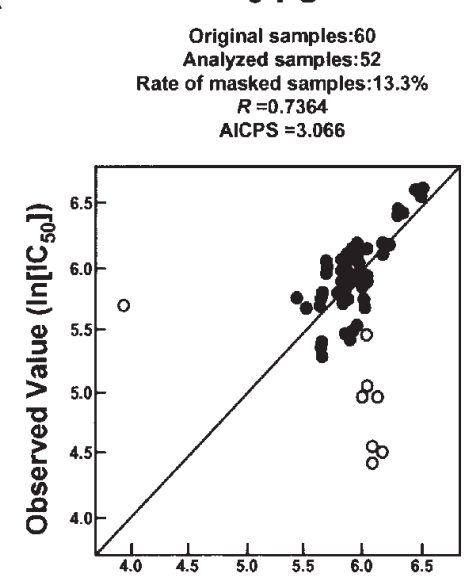

B

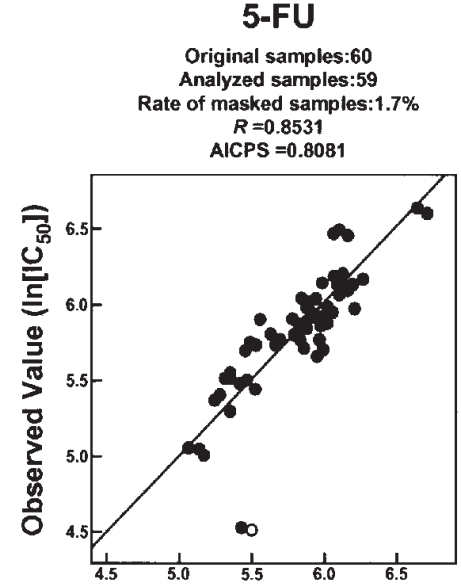

DOX
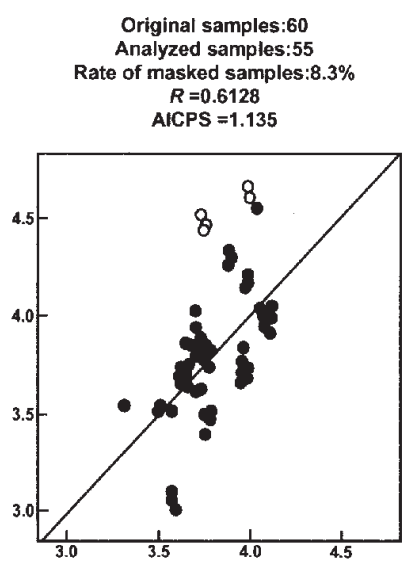

Fitted Value $\left(\ln \left[\mathrm{IC}_{50}\right]\right)$

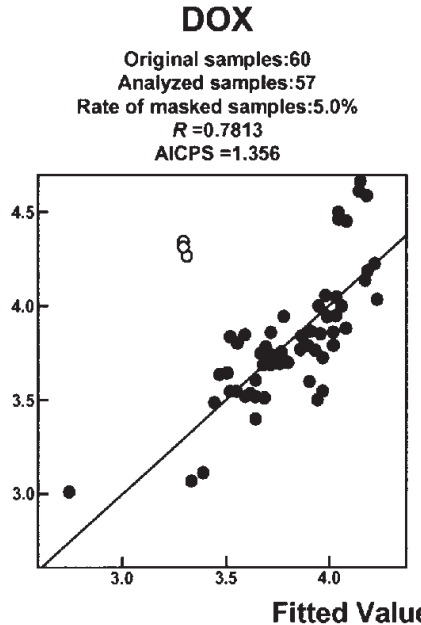

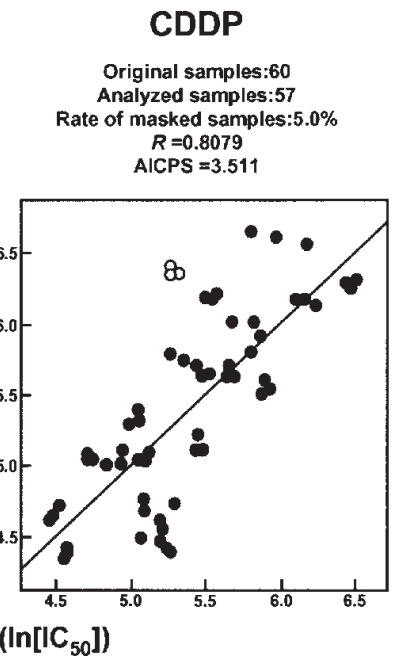

CDDP

CPT-11

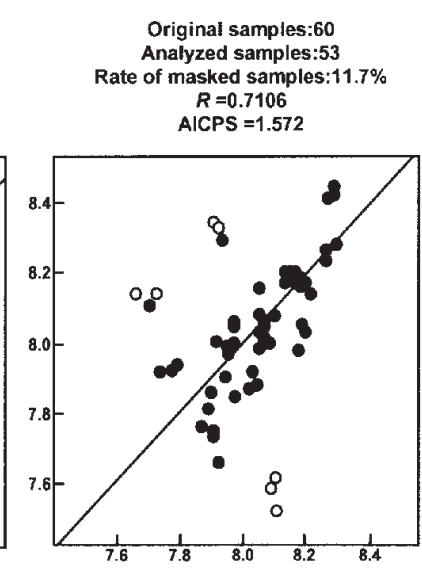

CPT-11
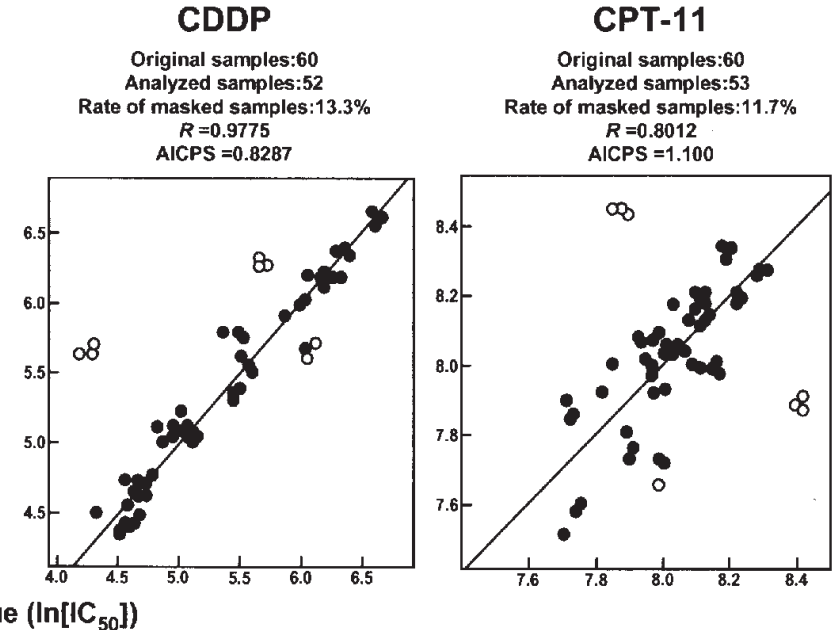

Figure 1. The relationship between observed $\mathrm{IC}_{50}$ value and fitted $\mathrm{IC}_{50}$ value calculated by fixed formulae for esophageal squamous cell carcinoma cell lines. We selected 5 functionally known genes for sensitivity to 5 drugs (A) and 9 highly correlative genes with sensitivity to 4 drugs in expression levels (B), as predictive marker genes through comprehensive gene expression analyses using cDNA and oligonucleotide microarrays and quantitative real-time RT-PCR. In this analysis, 60 independent data sets, composed by expression levels of selected genes and $\mathrm{IC}_{50}$ values for $20 \mathrm{KYSE}$ cell lines, were used. A vertical axis and a horizontal axis show observed and fitted $\mathrm{IC}_{50}$ values (both are logarithmically transformed), respectively. A closed circle indicates analyzed sample data, while an open circle indicates a masked outlier.

These approaches provided 4 prediction formulae of drug sensitivity in vitro when we used 5 genes known as sensitivity determinants and 9 genes selected from expression-sensitivity correlation analysis alone. The obtained $\theta_{p}$ is shown with p-value in Table II. Since the lower p-value indicates lower probability in order to demonstrate that $\theta$-value could be 0 in the prediction formula, genes showing lower p-values can be estimated as more important in drug sensitivity prediction: The expression level is of value as the explanatory variable in the formula. As expected, the genes previously suggested as important sensitivity determinant maintained their significance in drug sensitivity prediction, i.e. $D P Y D$ for 5-FU, BCL2 for DOX, GSTP1 for CDDP, XRCC1 for CPT-11, and MGMT for $\mathrm{SN}-38$ (Table IIA). The prediction formulae using expression data of 9 genes selected by expression-sensitivity correlation analysis alone also demonstrated that most of the selected genes played important roles in prediction: B4GALT5 and $U G C G$ for 5-FU; NRCAM for DOX; ARFRPI and IFITMI for CDDP; and $C A L U$ for CPT-11, despite some unexpected data such as XBP1 for 5-FU, and KIAA0685 and SIPAIL2 for CDDP (Table IIB). A positive $\theta$ indicates that the corresponding explanatory variable, gene expression, acts as a resistant factor in the prediction formulae, while a negative $\theta$ indicates the inverse action of the variable. Nevertheless, the levels of $\theta$-value do not directly account for the importance of the explanatory variable, since the expression levels of genes differ considerably from one another. All of the prediction formulae provided showed relatively high fitness, but the obtained correlation coefficients (R) and AIC for each sample (AICPS) suggested the limited value of the 4 formulae using 5 known sensitivity determinant genes in drug sensitivity prediction (Fig. 1A). The R-values and the AIPCS values were, respectively, lower and higher than those in the prediction formulae composed of 9 functionally unproven genes selected by expression-sensitivity correlation analysis alone (Fig. 1B).

Prediction model for clinical response to 5-FU-based chemotherapy. Using the same sets of genes, we attempted to construct a clinical application model through the investigation of clinical samples and their response data. Since 5-FU-based 
Table III. Explanatory variables $\left(x_{i p}\right)$ and estimated coefficients $\left(\theta_{p}\right)$ in prediction formulae for clinical response to 5-FU-based adjuvant chemotherapy.

A) Prediction formulae using 5 functionally known genes. $\theta_{p}$

\begin{tabular}{lcc}
\cline { 2 - 3 }$x_{i p}$ & Overall survival & Disease-free survival \\
\hline $\ln [B C L 2]$ & $-0.920(0.110)$ & $-1.105(0.144)$ \\
$\ln [D P Y D]$ & $0.203(0.604)$ & $0.455(0.389)$ \\
$\ln [G S T P 1]$ & $0.313(0.726)$ & $0.219(0.853)$ \\
$\ln [M G M T]$ & $0.863(0.064)$ & $1.100(0.072)$ \\
$\ln [X R C C 1]$ & $0.451(0.300)$ & $0.426(0.451)$ \\
$\varepsilon_{\mathrm{i}}$ & 5.398 & 4.954 \\
\hline
\end{tabular}

B) Prediction formulae using 9 highly correlative genes.

$$
\theta_{p}
$$

$\begin{array}{lll}x_{i p} & \text { Overall survival Disease-free survival }\end{array}$

\begin{tabular}{lcr}
\hline $\ln [$ ARFRPI] & $0.669(0.744)$ & $0.852(0.722)$ \\
$\ln [$ B $4 G A L T 5]$ & $0.125(0.928)$ & $0.336(0.836)$ \\
$\ln [$ CALU] & $-0.115(0.936)$ & $-0.298(0.859)$ \\
$\ln [$ IFITM1] & $0.000^{\mathrm{a}}(1.000)$ & $-0.029(0.981)$ \\
$\ln [$ KIAA0685] & $-0.319(0.859)$ & $-0.197(0.925)$ \\
$\ln [$ NRCAM] & $-0.680(0.223)$ & $-0.588(0.345)$ \\
$\ln [$ SIPAIL2] & $0.623(0.445)$ & $0.652(0.490)$ \\
$\ln [$ UGCG] & $-0.252(0.915)$ & $-0.548(0.842)$ \\
$\ln [$ XBPI] & $-0.069(0.954)$ & $0.195(0.888)$
\end{tabular}

$\varepsilon_{\mathrm{i}}$

6.005

5.519

[ ], expression level of indicated gene; ( ), p-value. ${ }^{a} 0.000528$.

chemotherapy is most commonly used as a post-operative adjuvant therapy for esophageal cancer in Japan, the prediction models for individual clinical response to 5-FU-based chemotherapy, in terms of overall survival (OS) and disease-free survival (DFS), were fixed. The expression levels of the selected marker genes in 14 tumor samples estimated by real-time RT-PCR were used to develop a prediction model and those in subsequently collected 4 tumors were used as test values to confirm the predictive accuracy of the model.

Since expression levels of DPYD, B4GALT5, UGCG and $X B P 1$ correlated with the therapeutic efficacy of 5-FU in vitro, we first investigated the correlation of the expression level in tumor samples and clinical response to 5-FU. However, none of the 4 genes alone could accurately predict clinical response to 5-FU therapy, either for OS or DFS. Since CDDP was administered with 5-FU, though at a low dose, we also studied predictive significance of GSTP1, ARFRP1, IFITM1, KIAA0685 and SIPA1L2, which correlated with CDDP sensitivity in vitro, and found limited predictive value for each of the 5 genes alone in clinical response to the adjuvant chemotherapy.
In contrast to these findings, application of combined expression data of either of the selected gene sets, 5 genes known as sensitivity determinants or 9 novel highly correlative genes, in 14 tumors in the predictive formulae for OS and DFS yielded the best linear models, and their predictive value was suggested by the consequent utility-confirmation analysis using subsequently analyzed 4 tumor samples (Table III and Fig. 2). We also constructed other potent prediction formulae using different sets of the marker genes, e.g. a set of GSTP1, ARFRP1, IFITMI and KIAA0685, but their predictive utilities estimated in test samples were not superior to those of the prediction formulae using either a set of the 5 genes or the 9 genes (data not shown).

\section{Discussion}

In this study, with a hypothesis that expression analysis of a set of the key drug sensitivity genes could allow us to predict therapeutic response to several active or potent agents in esophageal cancers simultaneously, we attempted to identify potent marker genes for 7 drugs (5-FU, MMC, DOX, CDDP, TXL, TXT, and CPT-11) and an active form of CPT-11, $\mathrm{SN}-38$. We were able to select 5 better marker genes known as drug sensitivity determinants and identify another 9-gene set as novel potent markers for 4 anticancer drugs [5-FU, CDDP, DOX, and CPT-11 (SN-38)] among the target drugs, through 2 different genome-wide microarray analyses and subsequent real-time RT-PCR. Despite the fact that the functional significance of the 9 genes in drug sensitivity is poorly understood, their expression levels were shown to be more highly correlative with cellular sensitivities to the 4 drugs than those of the 5 known drug sensitivity genes. We then determined expression data of the 2 sets of genes quantified by real-time RT-PCR as probable predictors and fixed the best linear model, which embraced the variable expressions of the component genes and arranged them in order to predict the efficacy of the drugs, using multiple regression analysis. These approaches provided 4 and 2 prediction formulae, respectively, for the in vitro activity of the 4 drugs and individual clinical responses to 5-FU-based post-operative adjuvant chemotherapy in terms of overall survival and disease free survival in each case, using a set of 5 known or 9 novel genes. All the fixed formulae appeared to be of predictive value, but the models using a set of 9 novel genes are likely to have more advantage in prediction.

We previously showed the first concise prediction models of the in vitro activity for 8 drugs (5-FU, CDDP, MMC, DOX, CPT-11, SN-38, TXL, and TXT) using various cancer cell lines, along with individual clinical responses to 5-FU using expression data of 12 genes selected from functionally proven genes alone (11). However, since biological behavior and the molecular basis of cancer differ significantly among cancer origins, it suggests the limited value of the prediction models in esophageal cancer. In fact, the potent marker genes selected in this study largely differed from those shown in our previous study. In the present study, no possible marker genes were suggested for MMC, TXL, or TXT in ESCC. Since they have not yet been approved as therapeutic agents for esophageal cancer, our data may explain the facts that the response of esophageal cancer to anticancer agents is peculiar 
A
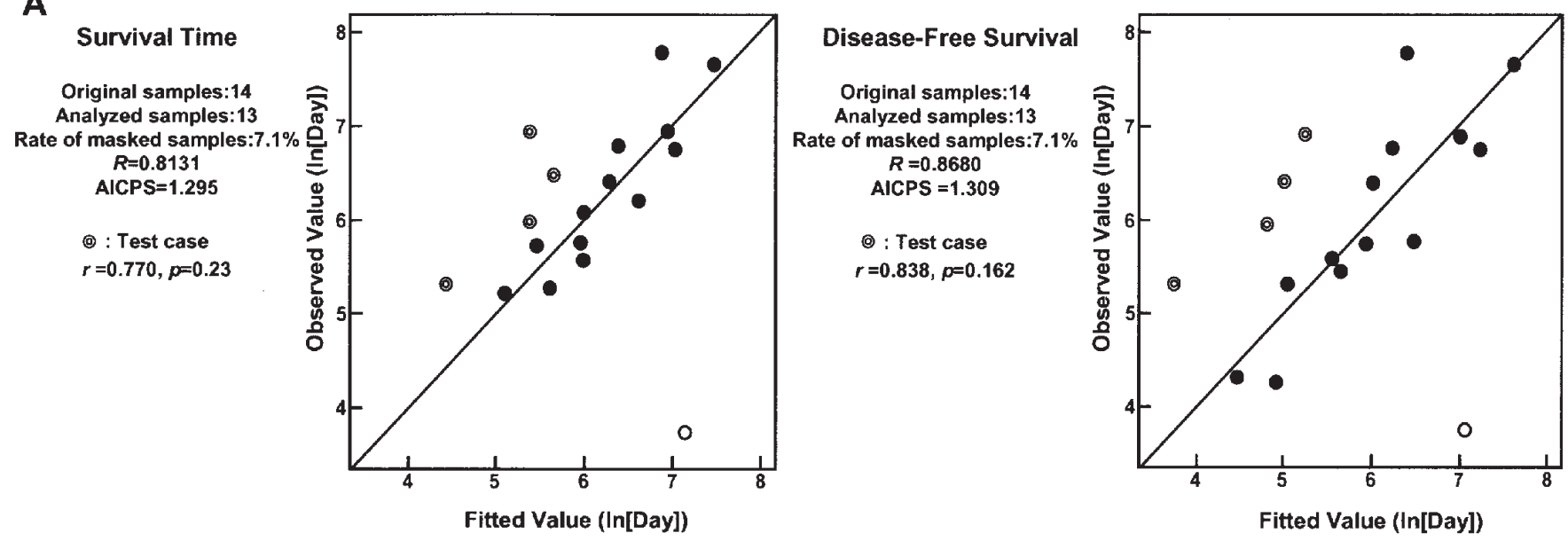

B
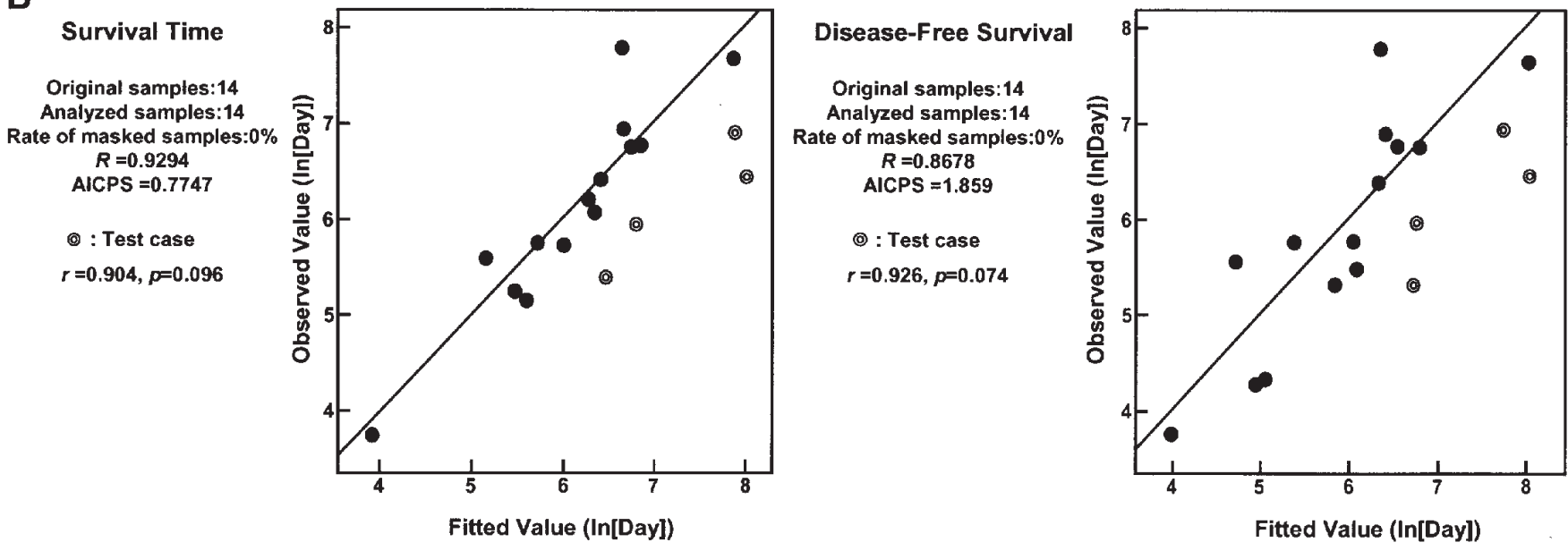

Figure 2. The relationship between observed value and fitted value calculated by fixed formulae for clinical response to 5-FU-based chemotherapy. We also developed formulae to predict the therapeutic efficacy of 5-FU-based chemotherapy, using the variable expression levels of 5 functionally known genes (A) or 9 highly correlative genes with sensitivity to 4 drugs in expression levels (B) which were selected by in vitro studies. A total of 14 tumor samples obtained earlier were used as experimental samples to develop a prediction model (a closed circle indicates analyzed sample data, while an open circle indicates a masked outlier), and subsequently obtained 4 samples, as test samples to confirm the predictive accuracy of the development model (double open circle). A vertical axis and a horizontal axis show observed value and fitted value (both are logarithmically transformed), respectively.

among cancers. ESCC probably has prominent prediction markers of its own due to its unique molecular basis.

Very few critical markers, however, have been validated to date for esophageal cancer, although there is clear evidence that a variety of genes are closely associated with cellular sensitivity to anticancer drugs in several cancers $(5,38,39)$. Although comprehensive gene expression analysis using DNA chip is a useful tool for the discovery of prediction markers, there has been no effective way to determine the critical marker genes from a huge number of candidates through expressionsensitivity correlation analysis alone. We can also create a prediction model for sensitivity of esophageal tumors to adjuvant chemotherapy using comprehensive gene expression analysis (40), but the practical value remains unknown. We therefore first determined the selection targets on genes already known as sensitivity determinants. All of the 5 selected genes in this study are considered to be among the most powerful for prediction of responses to the 4 drugs. The correlation of the 5 known genes with drug sensitivity, such as DPYD for 5-FU, BCL2 for DOX, GSTP1 for CDDP, XRCC1 for CPT-11, and $M G M T$ for SN-38, were confirmed in both comprehensive and quantified gene expression analysis, and numerous model systems and clinical studies have demonstrated their functional significance as indicators of drug sensitivity, even when used alone $(18,21,22,27,30-34)$. Even so, the individual correlation with drug sensitivity was too weak to show potent values as prediction markers.

The biological functions of the 9 newly selected genes (another set of potent prediction markers) remain poorly understood; however, they are more correlative with corresponding drug sensitivity than the 5 known genes in their expression levels. The functions of the 9 genes were little known to date: ARFRPI encodes a protein localized in the trans-Golgi network, and may maintain the normal secretory function of the cell; B4GALT5 is responsible for the synthesis of oligosaccharides in many glycoproteins as well as the carbohydrate moieties of glycolipids; $C A L U$ encodes a $\mathrm{Ca}^{2+}$ binding protein localized in the endoplasmic reticulum (ER), involved in such ER functions as protein folding and sorting; IFITM1 has been suggested as playing a role in the antiproliferative activity of interferons; NRCAM encodes a cell adhesion molecule specific to the nervous system and the 
molecule modulates neurite outgrowth and guidance via multiple interactions with different proteins; UGCG product catalyzes the first glycosylation step in glycosphingolipid biosynthesis; $X B P 1$ encodes an active transcription factor inducing expression of genes in ER (41-47); the functions of KIAA0685 and SIPAIL2 are not known to date. Although the selection approaches differed, these 2 sets of genes ( 5 known and 9 novel genes) may be better current candidates for prediction markers of drug response in ESCC. We therefore developed prediction models using the expression data of each set of the selected genes.

The fact that drug sensitivity is determined by multiple genes required a better understanding of the intricate network of the selected genes in the expression levels. In the present study, we used multiple regression analysis and reached the prediction formulae of in vitro drug activity and clinical response to 5-FU-based chemotherapy, and found that evaluation of the variable expression of the 2 sets of selected genes appeared to work well in the prediction model, even though none of the selected genes alone could accurately predict drug response. It is obvious that practical usefulness needs to be evaluated by a prospective study, but the fixed prediction formulae, especially the formulae using expression data of 9 novel genes, showed high predictive potential. These results suggest that simultaneous performance of two different types of comprehensive gene expression analysis, cDNA and oligonucleotide microarray analyses, may provide a way to identify potent marker genes from the expression-sensitivity correlation analysis alone. We believe our approach is one of the most practical methods available at present to identify more reliable novel prediction markers of drug response. The functional roles of the selected 9 genes in drug sensitivity are the focus of our intensive continuing study.

Nevertheless, in the clinical application models, the key genes in the prediction models somewhat vary from those in an in vitro prediction system. We hypothesized that the significance of truly useful genes would not be affected by other unnecessary genes in such a prediction system, which was confirmed in our in vitro prediction system but not in the clinical application models. The p-value for each $\theta_{p}$ demonstrated that there was no key gene in the prediction formulae. Although the precise reasons are unclear at present, heterogeneity of the tumor samples and unsettled administered doses of CDDP among patients might have influenced the results. We are now planning a prospective clinical study to clarify the reasons and evaluate the practical value, along with continuing our search for more powerful predictive marker genes for drug sensitivity.

\section{Acknowledgements}

We thank Dr Yutaka Shimada (Kyoto University) for his kind supply of 20 KYSE cell lines with helpful advices for the culture. We also thank Chiyo Oda for her technical assistance in MTT assay. Part of this study was supported by Grant from The Science Promotion Fund of the Ministry of Education, Culture, Sports, Science and Technology of Japan, Grant-in-Aid for Scientific Research (B) (2) (no. 14370390, to M.N.) and Grant-in-Aid for University and Industry Collaboration (A) (to M.N.).

\section{References}

1. Koshy M, Esiashvilli N, Landry JC, Thomas CR Jr and Matthews RH: Multiple management modalities in esophageal cancer: epidemiology, presentation and progression, work-up, and surgical approaches. Oncologist 9: 137-146, 2004.

2. Ancona E, Ruol A, Santi S, Merigliano S, Sileni VC, Koussis H, Zaninotto G, Bonavina L and Peracchia A: Only pathologic complete response to neoadjuvant chemotherapy improves significantly the long term survival of patients with resectable esophageal squamous cell carcinoma: final report of a randomized, controlled trial of preoperative chemotherapy versus surgery alone. Cancer 91: 2165-2174, 2001.

3. Ando N, Iizuka T, Ide H, Ishida K, Shinoda M, Nishimaki T, Takiyama W, Watanabe H, Isono K, Aoyama N, Makuuchi H, Tanaka O, Yamana H, Ikeuchi S, Kabuto T, Nagai K, Shimada Y, Kinjo Y and Fukuda H: Surgery plus chemotherapy compared with surgery alone for localized squamous cell carcinoma of the thoracic esophagus: a Japan Clinical Oncology Group Study-JCOG9204. J Clin Oncol 21: 4592-4596, 2003.

4. Tak VM and Naunheim KS: Current status of multimodality therapy for esophageal carcinoma. J Surg Res 117: 22-29, 2004.

5. Adlard JW, Richman SD, Seymour MT and Quirke P: Prediction of the response of colorectal cancer to systemic therapy. Lancet Oncol 3: 75-82, 2002.

6. Evans WE and Relling MV: Pharmacogenomics: translating functional genomics into rational therapeutics. Science 286: 487-491, 1999.

7. Iqbal S and Lenz HJ: Targeted therapy and pharmacogenomic programs. Cancer 97: 2076-2082, 2003.

8. Scherf U, Ross DT, Waltham M, Smith LH, Lee JK, Tanabe L, Kohn KW, Reinhold WC, Myers TG, Andrews DT, Scudiero DA, Eisen MB, Sausville EA, Pommier Y, Botstein D, Brown PO and Weinstein JN: A gene expression database for the molecular pharmacology of cancer. Nat Genet 24: 236-244, 2000.

9. McLeod HL and Evans WE: Pharmacogenomics: unlocking the human genome for better drug therapy. Annu Rev Pharmacol Toxicol 41: 101-121, 2001.

10. Staunton JE, Slonim DK, Coller HA, Tamayo P, Angelo MJ, Park J, Scherf U, Lee JK, Reinhold WO, Weinstein JN, Mesirov JP, Lander ES and Golub TR: Chemosensitivity prediction by transcriptional profiling. Proc Natl Acad Sci USA 98: 10787-10792, 2001

11. Tanaka T, Tanimoto K, Otani K, Satoh K, Ohtaki M, Yoshida K, Toge T, Yahata H, Tanaka S, Chayama K, Okazaki Y, Hayashizaki Y, Hiyama K and Nishiyama M: Concise prediction models of anticancer efficacy of 8 drugs using expression data from 12 selected genes. Int J Cancer 111: 617-626, 2004

12. Morita T, Togo S, Kubota T, Kamimukai N, Nishizuka I, Kobayashi T, Ichikawa Y, Ishikawa T, Takahashi S, Matsuo K, Tomaru Y, Okazaki Y, Hayashizaki Y and Shimada H: Mechanism of postoperative liver failure after excessive hepatectomy investigated using a cDNA microarray. J Hepatobiliary Pancreat Surg 9: 352-359, 2002.

13. Hiyama K, Otani K, Ohtaki M, Satoh K, Kumazaki T, Takahashi T, Mitsui Y, Okazaki Y, Hayashizaki Y, Omatsu H, Noguchi T, Tanimoto K and Nishiyama M: Differentially expressed genes throughout the cellular immortalization processes are quite different between normal human fibroblasts and endothelial cells. Int J Oncol 27: 87-95, 2005.

14. Ohtaki M, Otani K, Satoh K, Kawamura T, Hiyama K and Nishiyama M: Model-based analysis of microarray data: exploration of differentially expressed genes between two cell types based on a two-dimensional mixed normal model. Jpn J Biometrics 26: 31-48, 2005.

15. Rousseeuw PJ: Least median of squares regression. J Am Statist Assoc 79: 871-880, 1984

16. Chung YM, Park S, Park JK, Kim Y, Kang Y and Yoo YD: Establishment and characterization of 5-fluorouracil-resistant gastric cancer cells. Cancer Lett 159: 95-101, 2000.

17. Cresteil T, Monsarrat B, Dubois J, Sonnier M, Alvinerie P and Gueritte F: Regioselective metabolism of taxoids by human CYP3A4 and 2C8: structure-activity relationship. Drug Metab Dispos 30: 438-445, 2002.

18. Davis JM, Navolanic PM, Weinstein-Oppenheimer CR, Steelman LS, Hu W, Konopleva M, Blagosklonny MV and McCubrey JA: Raf-1 and Bcl-2 induce distinct and common pathways that contribute to breast cancer drug resistance. Clin Cancer Res 9: 1161-1170, 2003. 
19. Diasio RB and Johnson MR: Dihydropyrimidine dehydrogenase: its role in 5-fluorouracil clinical toxicity and tumor resistance. Clin Cancer Res 5: 2672-2673, 1999.

20. Gorrini C, Donzelli M, Torriglia A, Supino R, Brison O, Bernardi R, Negri C, Denegri M, Counis MF, Ranzani GN and Scovassi AI: Effect of apoptogenic stimuli on colon carcinoma cell lines with a different c-myc expression level. Int J Mol Med 11: 737-742, 2003.

21. Goto S, Ihara Y, Urata Y, Izumi S, Abe K, Koji T and Kondo T: Doxorubicin-induced DNA intercalation and scavenging by nuclear glutathione S-transferase $\pi$. FASEB J 15: 2702-2714, 2001.

22. Goto S, Kamada K, Soh Y, Ihara Y and Kondo T: Significance of nuclear glutathione S-transferase $\pi$ in resistance to anticancer drugs. Jpn J Cancer Res 93: 1047-1056, 2002.

23. Grassilli E, Ballabeni A, Maellaro E, Del Bello B and Helin K: Loss of MYC confers resistance to doxorubicin-induced apoptosis by preventing the activation of multiple serine protease- and caspase-mediated pathways. J Biol Chem 279: 21318-21326, 2004.

24. Hayes MC, Birch BR, Cooper AJ and Primrose JN: Cellular resistance to mitomycin $\mathrm{C}$ is associated with overexpression of MDR-1 in a urothelial cancer cell line (MGH-U1). BJU Int 87: 245-250, 2001

25. Hidaka S, Yasutake T, Fukushima M, Yano H, Haseba M, Tsuji T, Sawai T, Yamaguchi H, Nakagoe T, Ayabe H and Tagawa Y: Chromosomal imbalances associated with acquired resistance to fluoropyrimidines in human colorectal cancer cells. Eur J Cancer 39: 975-980, 2003.

26. Iida T, Mori E, Mori K, Goto S, Urata Y, Oka M, Kohno S and Kondo T: Co-expression of gamma-glutamylcysteine synthetase sub-units in response to cisplatin and doxorubicin in human cancer cells. Int J Cancer 82: 405-411, 1999.

27. Knowlton K, Mancini M, Creason S, Morales C, Hockenbery D and Anderson BO: Bcl-2 slows in vitro breast cancer growth despite its antiapoptotic effect. J Surg Res 76: 22-26, 1998.

28. Maitra R, Halpin PA, Karlson KH, Page RL, Paik DY, Leavitt MO, Moyer BD, Stanton BA and Hamilton JW: Differential effects of mitomycin C and doxorubicin on P-glycoprotein expression. Biochem J 355: 617-624, 2001.

29. Nishiyama M, Suzuki K, Kumazaki T, Yamamoto W, Toge T, Okamura T and Kurisu K: Molecular targeting of mitomycin C chemotherapy. Int J Cancer 72: 649-656, 1997.

30. Noguchi T, Tanimoto K, Shimokuni T, Ukon K, Tsujimoto H, Fukushima M, Noguchi T, Kawahara K, Hiyama K and Nishiyama M: Aberrant methylation of DPYD promoter, DPYD expression, and cellular sensitivity to 5-fluorouracil in cancer cells. Clin Cancer Res 10: 7100-7107, 2004.

31. Okamoto R, Takano H, Okamura T, Park JS, Tanimoto K, Sekikawa T, Yamamoto W, Sparreboom A, Verweij J and Nishiyama M: $O(6)$-methylguanine-DNA methyltransferase (MGMT) as a determinant of resistance to camptothecin derivatives. Jpn J Cancer Res 93: 93-102, 2002.

32. Park SY, Lam W and Cheng YC: X-ray repair cross-complementing gene I protein plays an important role in camptothecin resistance. Cancer Res 62: 459-465, 2002.
33. Plo I, Liao ZY, Barcelo JM, Kohlhagen G, Caldecott KW, Weinfeld M and Pommier Y: Association of XRCC1 and tyrosyl DNA phosphodiesterase (Tdp1) for the repair of topoisomerase Imediated DNA lesions. DNA Repair 2: 1087-1100, 2003.

34. Pourquier P, Waltman JL, Urasaki Y, Loktionova NA, Pegg AE, Nitiss JL and Pommier Y: Topoisomerase I-mediated cytotoxicity of N-methyl-N'-nitro-N-nitrosoguanidine: trapping of topoisomerase I by the O6-methylguanine. Cancer Res 61: 53-58, 2001

35. Rasheed ZA and Rubin EH: Mechanisms of resistance to topoisomerase I-targeting drugs. Oncogene 22: 7296-7304, 2003.

36. Tani M, Goto S, Kamada K, Mori K, Urata Y, Ihara Y, Kijima H, Ueyama Y, Shibata S and Kondo T: Hammerhead ribozyme against gamma-glutamylcysteine synthetase attenuates resistance to ionizing radiation and cisplatin in human $\mathrm{T} 98 \mathrm{G}$ glioblastoma cells. Jpn J Cancer Res 93: 716-722, 2002.

37. Thomas CJ, Rahier NJ and Hecht SM: Camptothecin: current perspectives. Bioorg Med Chem 12: 1585-1604, 2004.

38. Clarke PA, te Poele R, Wooster R and Workman P: Gene expression microarray analysis in cancer biology, pharmacology, and drug development: progress and potential. Biochem Pharmacol 62: 1311-1336, 2001.

39. Watters JW and McLeod HL: Cancer pharmacogenomics: current and future applications. Biochim Biophys Acta 1603: 99-111, 2003.

40. Kihara C, Tsunoda T, Tanaka T, Yamana H, Furukawa Y, Ono K, Kitahara O, Zembutsu H, Yanagawa R, Hirata K, Takagi T and Nakamura Y: Prediction of sensitivity of esophageal tumors to adjuvant chemotherapy by cDNA microarray analysis of gene-expression profiles. Cancer Res 61: 6474-6479, 2001.

41. Akyerli CB, Beksac M, Holko M, Frevel M, Dalva K, Ozbek U, Soydan E, Ozcan M, Ozet G, Ilhan O, Gurman G, Akan H, Williams BR and Ozcelik T: Expression of IFITM1 in chronic myeloid leukemia patients. Leuk Res 29: 283-286, 2005.

42. Burd CG, Strochlic TI and Gangi Setty SR: Arf-like GTPases: not so Arf-like after all. Trends Cell Biol 14: 687-694, 2004.

43. Grumet M: Nr-CAM: a cell adhesion molecule with ligand and receptor functions. Cell Tissue Res 290: 423-428, 1997.

44. Ichikawa S, Sakiyama H, Suzuki G, Hidari KI and Hirabayashi Y: Expression cloning of a cDNA for human ceramide glucosyltransferase that catalyzes the first glycosylation step of glycosphingolipid synthesis. Proc Natl Acad Sci USA 93: 4638-4643, 1996.

45. Paschen W: Endoplasmic reticulum: a primary target in various acute disorders and degenerative diseases of the brain. Cell Calcium 34: 365-383, 2003.

46. Sato T, Furukawa K, Bakker H, van den Eijnden DH and van Die I: Molecular cloning of a human cDNA encoding beta1,4-galactosyltransferase with $37 \%$ identity to mammalian UDP-Gal:GlcNAc beta-1,4-galactosyltransferase. Proc Natl Acad Sci USA 95: 472-477, 1998.

47. Yabe D, Taniwaki M, Nakamura T, Kanazawa N, Tashiro K and Honjo T: Human calumenin gene (CALU): cDNA isolation and chromosomal mapping to 7q32. Genomics 49: 331-333, 1998. 